well be incomprehensible to (say) a biologist needing to buy an AA instrument to study mercury concentrations in lichens or fungi. Ignoring the edited commercial specifications and accounts in the main section of the text, one goes on to the summary provided by the author at the end. Here there are many valuable expressions of opinion and discussions of "pros and cons" of prisms against gratings, meter against digital read-out, single against double beam facility and so on. The author groups instrumentation into categories according to price range, versatility, and so on, and narrows down the field to a fairly simple choice according to the purchaser's budget and requirements. This section has very considerable merit though one cannot but reflect that its value may be rather transient since instruments become obsolete so quickly, and of course the prices can only be regarded as very approximate.

One of the most interesting features is the author's first assessment of the flame emission technique in the second paragraph of the preface and the caveat introduced in the penultimate paragraph of the final section of the book largely due to the strenuous "emission" lobbying of Professor Fassel's group at Iowa State University. It is true to a limited extent that the higher monochromator cost of a good emission instrument is partly offset by the cost of hollow cathode lamps for atomic absorption. But the view expressed that a high-capability emission instrument can easily perform AA is only true when that "expensive" instrument is further provided with the necessary "expensive" power supply and, of course, "expensive" hollow cathode lamps. Emission in flames is certainly a valuable and indispensable technique for trace analysis of elements such as the alkali metals and several others but good emission instrumentation is more complicated to use and it is very doubtful now if it will ever seriously challenge its younger atomic absonption sister for the generality of trace metals analysis. Radio frequency plasma emission methods show a little more promise, but the multielement capability, simplicity and sensitivity of non-dispersive atomic fluorescence spectroscopy are much more likely to offer most challenge to atomic absorption.

This is a useful book but it may become very much out of date very quickly, particularly in this ebullient area of atomic absorption spectroscopy. Other books in the series are proposed for thermoanalysis, nuclear magnetic resonance, X-ray fluorescence, gasliquid chromatography, mass spectrometry, and so on. If this is a foretaste of the others in the series, I can but reply to the terminal two-word sentence of the text "Good luck" by saying "Thanks a lot".

T. S. WEST

\section{Mathematics in Schools}

The School Mathematics Project: The First Ten Years-Being Primarily the Collection of the Directors' Reports for the Years 1961-71. By Bryan Thwaites. Pp. $\mathrm{x}+266$. (London: Cambridge University Press, 1972.) $£ 3$ cloth, $£ 1.50$ paper.

THE SMP is a splendidly English institution: self-confident, pragmatic, freeenterprise. It started not in a Ministry of Education nor in a faculty lounge but in a Winchester garden. Its initial objective was "the evolution of a syllabus for the whole grammar school range of $11+$ to 18 , which will adequately reflect the modern trends and usages of mathematics; and the production of a complete set of associated textbooks and teachers' guides". Eleven years and nine directors' reports later, it has produced the books, run an impressive number of courses for teachers, fought and won against universities and examination boards, and expanded to include a wider spectrum of children.

The growth story is a fascinating one, told here in the reports by the project's rumbustious director, Bryan Thwaites. A short article at the end by deputy director Douglas Quadling gives interesting arguments for the inclusion of various topics-linear programming, networks, statistics, matrices, and so on. A great strength of SMP has been its flexibility: the period of self-torture in attempting to do all geometry by transformations is mercifully over, and there is a growing realization that some of the old techniques are still useful after all.

It is easier to criticize than to create. It could be argued that the children should have more relative consideration than the mathematics-how do SMP (and CSM and MME and SMG ...) judge the degrees of difficulty and appropriateness of their selected topics? How, in fact, do children learn? But certainly the quickest way to a first answer to these questions is to write and see. Another criticism is that SMP has ignored the demands of other subjects, notably physics, but there is an element of "pot and kettle" here, and anyway there was so much to be reformed within a subject without looking sideways. A third criticism could be made of "export SMP"- - what is the likelihood of this English venture being really appropriate elsewhere?-but mercifully this seems to be either on the decline or being handed over to the natives for treatment.

SMP will occasionally get its fingers burned (the story of the international project for computing in schools is hilarious, the countries concerned being England and an uncooperative Scotland) but it has played a tremendous role in getting English school mathematics into this century, and trial and error by dedicated teachers will probably continue to pay off for at least another ten years.

Geoffrey MatTHEWs

\section{Rational Enquiry}

The Pluralist and Possibilist Aspect of Scientific Enterprise. By Arne Naess. Pp. 147. (Universitetforlaget: Oslo; George Allen and Unwin: London, July 1972.) $£ 4$.

Professor NAEss can be pleased that the philosophical world is catching up with him. As he reminds us, the Vienna Circle of the 1920 s and 30 s was a somewhat missionary movement for "rationality" against reactionary forms of metaphysics, and it simply took physics as the paradigm of true knowledge. By contrast, Naess even then appreciated the plurality of genuinely scientific disciplines, and also of theories and approaches within a discipline, as of psychology.

Now, a long time later, he sees himself vindicated by the new pluralistic philosophies of science, notably of Kuhn, but with the implicit agreement of Lakatos. In this vein, he develops some slightly formalized descriptions of scientific choice and change, and also discourses widely over problems in the study of science.

His discussion is most coherent with English-language philosophy of science when it touches on Kuhn and the inescapable relativism of his conception of "scientific revolution" as a clash between incommensurable paradigms. Applying such a scheme to the writing of history and philosophy of science, including Kuhn, he shows that the inevitable paradoxes of self-reference are encountered. But handling these in the light of traditions of methodology of scholarship in general, he arrives at some genuinely interesting conclusions. Among these is that a truly comprehen. sive and consistent "point of view" cannot be explicitly chosen by an individual (for the conscious choice itself involves criteria belonging to one point of view or another). Hence the real changes that individuals experience in their world-views must occur from a more diffuse set of stimuli, and must proceed through less consistent intermediate stages.

A practical corollary of this conclusion is that pluralism, rather than exclusive domination by one or another system, is the only sane and effective style for science and rational enquiry in general. It is to be hoped that this message can be imparted to Professor Naess's new colleagues in the environmental field (where he now devotes his energies); simplistic philosophies of science are a luxury they cannot afford. J. R. RAVETZ 